\title{
THE ABSOLUTE SPEED OF CHANGE: MULTIDIMENSIONAL SCALING AND INNOVATION RATES*
}

\author{
M. HINZ† and J. MÜLLER \\ Institut für Ur- und Frühgeschichte, Christian-Albrechts-Universität zu Kiel, Johanna-Mestorf-Str. 2-6, \\ Kiel 24118, Germany
}

\begin{abstract}
The evaluation of societal developments depends on a clear determination of the rate of change that occurs within societies. While many statistical approaches are able to indicate similarity/dissimilarity distances between archaeological assemblages, only a few can be linked to linear timescales. In the following approach, the advantages of non-metric multidimensional scaling (NMDS) are described as a method that produces gradients for a quantitative measurement of cultural change on a linear timescale. Thus, the speed of innovations or the regression of cultural developments could be quantified. In consequence, a quantified proxy of societal developments on a linear timescale is provided. In two examples, the usefulness of such a proxy is described in relation to other data.

KEYWORDS: ${ }^{14} \mathrm{C}$, CALIBRATION, NON-METRIC MULTIDIMENSIONAL SCALING, CORRESPONDENCE ANALYSIS, INNOVATION, CULTURAL DEVELOPMENT, TYPOLOGY, NEOLITHIC, BRONZE AGE
\end{abstract}

\section{CULTURAL CHANGE AND THE LINEAR TIMESCALE}

The success of a reconstruction of prehistoric societies is contingent on the ability of archaeologists to trace back both the chronology as well as the spatial distribution of phenomena. Changes in material culture are due to communication and interaction of producers, distributors and consumers within certain timescales and over specific social and geographical spaces. One of the preconditions for evaluating different changes within societies is the reconstruction of the speed and intensity of changes that are visible in prehistory; for example, in typological changes of material culture.

While such an approach appears to be undemanding, the real verification of the speed of changes is quite an elaborate task. One of the most common approaches is the comparison of stratigraphical information or information won by the scientific dating of typological differences; for example, in ceramic types, architectural types, depositional processes or the like. Typology is a method of describing the similarities or dissimilarities between types or assemblages, which might be due to differences in chronology, social functions, religious behaviour or other structures. Typological differences can be identified as chronologically relevant by the use of ${ }^{14} \mathrm{C}$ measurements or other scientific dating methods and by vertical stratigraphies (e.g., Müller 2009).

As a result, we end up with chronological frameworks that are, at best, not very precise, as typological differences might be interpreted as chronological sequences, but without a quantification of the rate of change. Ideally, we search for a method by which a quantification of the

\footnotetext{
*Received 18 November 2013; accepted 27 February 2014

†Corresponding author: email martin.hinz@ufg.uni-kiel.de

(C) 2014 University of Oxford
} 
dissimilarity rate of material culture (e.g., of decoration patterns) is expressed. In a second step, the quantified gradient has to be identified as chronologically relevant by the use of scientific dates and/or vertical stratigraphies. Nevertheless, a third step is necessary to achieve an absolute timescale: as cultural changes (thus typological developments) do not necessarily occur with the same speed (as societal and cultural events certainly influence human behaviour in a non-linear manner), the gradient of - for example_-dissimilarities in ceramic decoration has to be stretched or compressed according to the absolute dates that are available by scientific dating methods. Thus, a further calibration step is essential.

One of the methods to order typological data in an (at least quasi-) quantitative way is seriation, at first presented notably by Petrie (1899). The method itself is based upon the assumption that the more similar the objects or assemblages are, the closer they are situated on a gradient. It is of interest that the method itself is very similar to the ordering that Oscar Montelius described in Die typologische Methode (1903). During the past few decades, these enquiries from the beginnings of scientific archaeology have been elaborated by statistical methods. Both reciprocal averaging and different types of correspondence analyses (CA) have been widely implemented to determine the similarities and dissimilarities on a quantitative scale (e.g., Madsen 1988; Müller and Zimmermann 1997).

The major drawback is that we only derive an ordinal scale, and not an absolute one, which is necessary to investigate the regression of temporal change through time and the speed of innovation.

The approach presented here is an attempt to combine the advantages of quantifying typological differences and absolute dating. It aims to calibrate typological gradients with available ${ }^{14} \mathrm{C}$ dates and to use the configuration of an ordination to estimate the speed of a cultural development. Moreover, with such a method it is possible to estimate the dates for sites more independently of preservation conditions and costs. To achieve this, we use non-metric multidimensional scaling (NMDS). As a result, we anticipate that the rate of change in prehistoric societies can be expressed for the first time by quantitative figures. The resulting curve of such a velocity could be compared with other available information on the time periods in question (e.g., contrasting cultural change with environmental change).

\section{FORMER APPROACHES}

One of the most common approaches to combining absolute dates with seriation is to divide the seriated arrangement of the sites into phases, for which the respective absolute dates are then used to pinpoint the whole phase on an absolute chronological axis. Such an approach is not very precise, not quantitative and we lose a lot of the available information present in the internal order (and distance) within specific phases. There is also no measurement of uncertainty for the phases (beyond the individual uncertainty of the absolute dates) and the division into phases is determined subjectively or with the help of rather explorative statistical tools (e.g., cluster analysis). One of the many examples for such an approach is the study by Jørgensen (1992), for early medieval sites in northern Italy.

Recently, Bellanger et al. $(2006,2008)$ presented a study in which they tried to use the coordinates of a CA of ceramics on the first principal axis in combination with coin dates to estimate the ages of sites in the medieval city of Tours that were not dated by coins. The coordinates were used in a regression model, in which the absolute date is a linear function of scores on this axis. The model was checked by bootstrapping methods and they obtained an estimation of the dates. 
This approach is quantitative, uses the information present in the (possibly temporal) order of the sites as well and even has a measurement of uncertainty. But a basic problem is still present in their method of connecting time and the progress of cultural change. The assumption that time can be handled as a linear function of cultural development (or vice versa) is at least questionable. Most archaeologists would agree that cultural development is not a linear process. Moreover, the results of a CA are values in a $\chi^{2}$ metric and are therefore non-linear. Time is a linear process (as long as we do not have to deal with Einstein's relativity). So the method assumes linearity where there is none (because cultural development is not linear) and uses a non-linear relation where the relation should be linear.

To illustrate this, we compare the CA and the NMDS of a test case of an ideal distribution with respect to the distances that the points have on the first dimension (Fig. 1). In case of the CA, the expected horseshoe pattern appears in the main plot and the distances between the points also form a parabola, whereas in the NMDS the layout of the dimensions and the plot of the distances are much more linear. It is obvious that if we use the CA, equally dissimilar sites are not equally spaced on the first dimension, whereas in the NMDS this placement better fulfils the requirement of linear mapping.

An alternative approach is to use a canonical correspondence analysis (CCA), wherein the absolute dates are used as the constraint for the ordination (e.g., Groenen and Poblome 2003; van de Velden et al. 2009). This technique is also very relevant for the estimation of dates for undated assemblages. Its disadvantage is that it is a direct ordination, so that the applied constraint is too rigid. The resulting scores on the canonical axes are linearly related to the introduced absolute dates, so that it cannot be used as an independent measurement of change. Currently, NMDS seems to be the best algorithm with which to obtain an independent, quasilinear mapping of dissimilarities that can subsequently be correlated to absolute dates in a second step.

\section{METHODS}

\section{Non-metric multidimensional scaling (NMDS)}

NMDS is not a new technique. The method, developed by Kruskal (1964) and introduced with an archaeological example by Kendall (1969), was used in archaeology in the 1970s and early 1980s for the seriation of material culture as well as for more elaborate tasks. But since then it seems that it has not been used very often in archaeology for chronological purposes and has been widely replaced (at least in Germany) by CA, although it is mentioned in some basic textbooks (Shennan 1988; Renfrew and Bahn 2000). At least in Central Europe and Scandinavia, it has been widely replaced by CA (Madsen 1988; Müller and Zimmermann 1997).

Unlike CA, which operates innately in a $\chi^{2}$ metric, in (N)MDS the resulting metric equals the metric of the distances entered in the first place. By choosing a metric for the distances that is at least almost Euclidean, it is possible to relate the result to vectors for the data that behave metrically - such as, for instance, time. In contrast to the values on the eigenvectors of the CA, the values of the NMDS factors can be used on a ratio scale for comparisons, given the appropriate metric of the distances in the first place.

The method itself is exhaustively described elsewhere (e.g., Kruskal 1964). The basic idea is to iteratively optimize a representation of the original data in lower dimensionality to best fit the distances of the original data set. We used the 'metaMDS' algorithm from the 'vegan' package of the R statistical environment. 


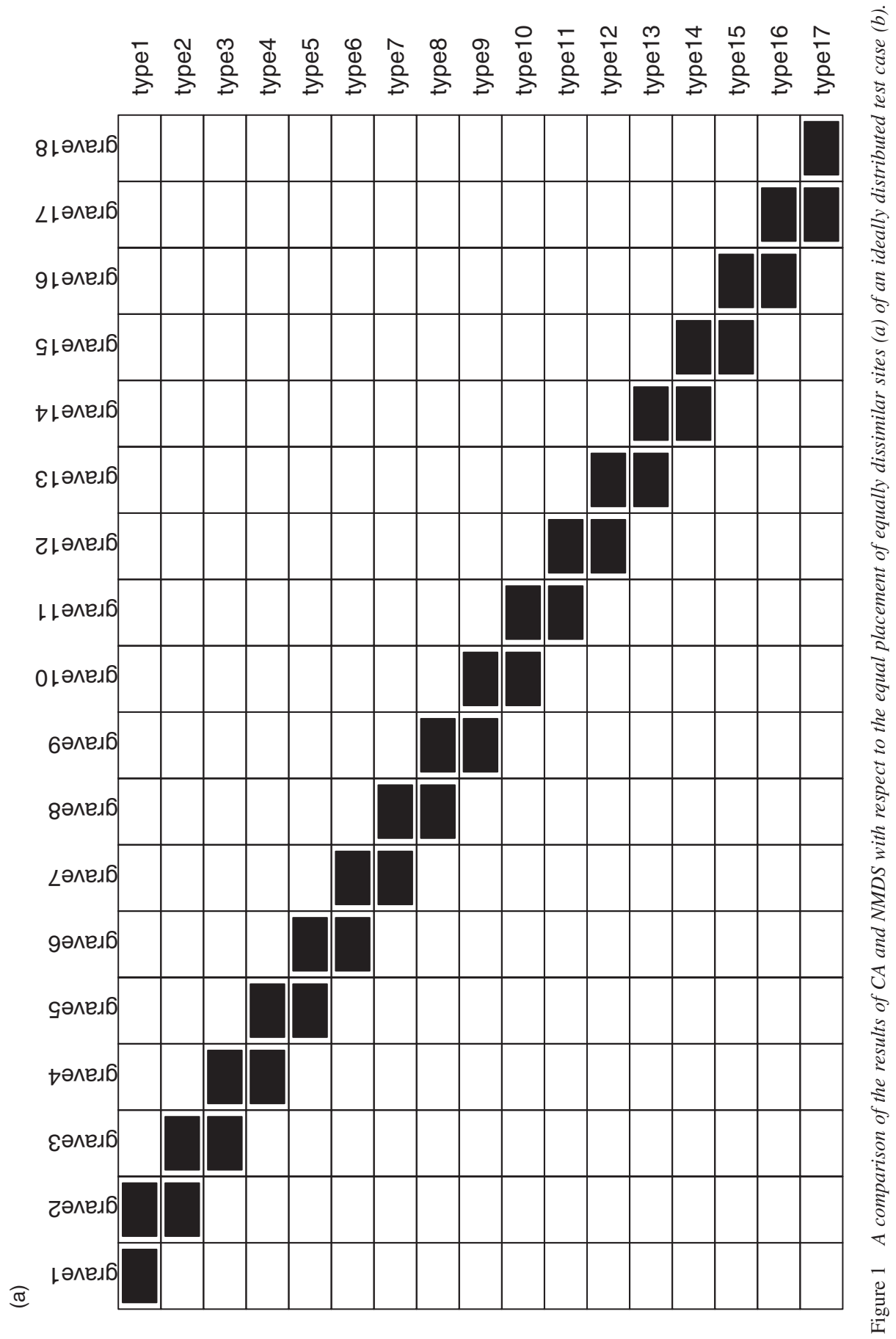



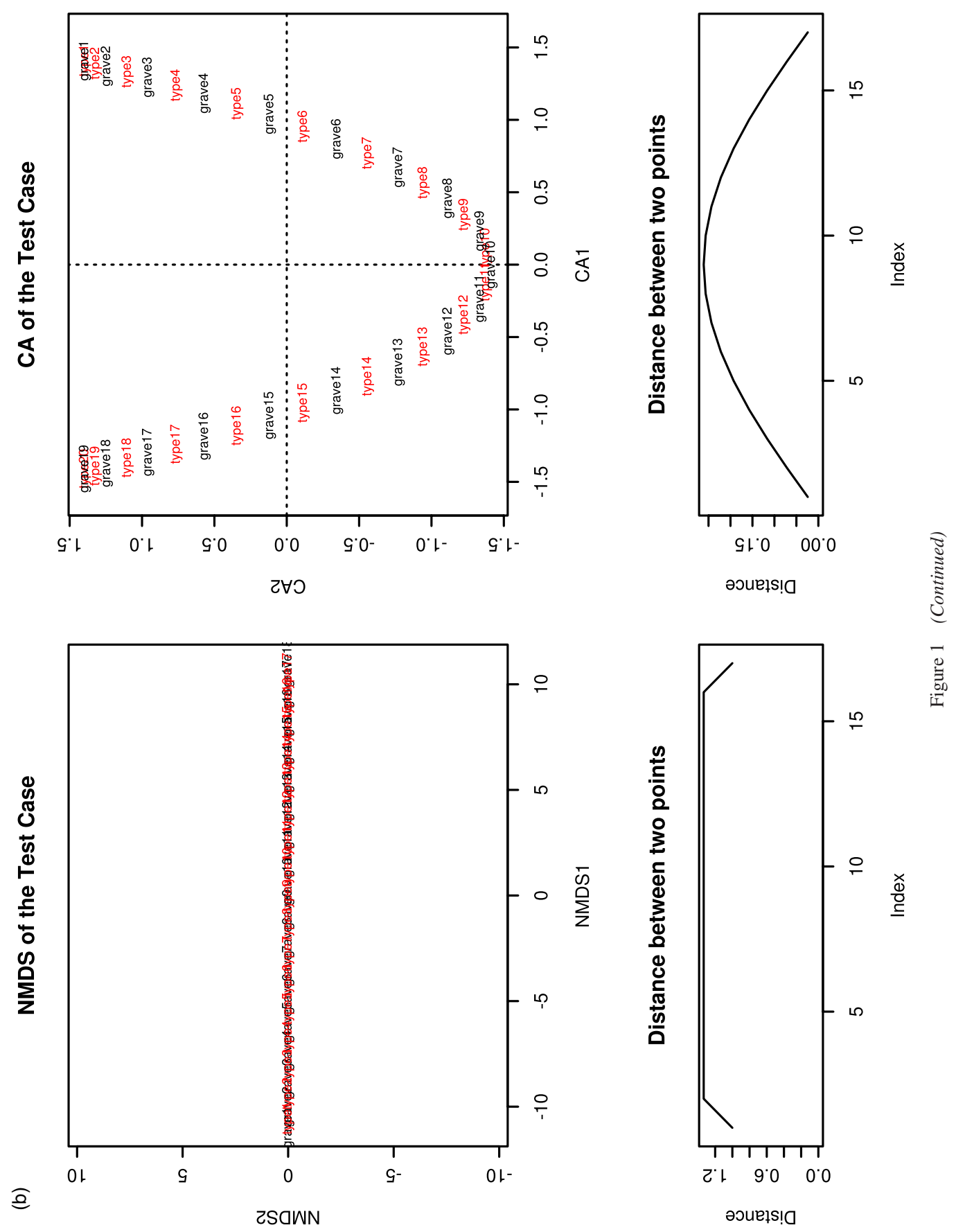


\section{The distance metric}

Graham, Galloway and Scollar proved in 1976 that, in combination with Jaccard's similarity index, NMDS is a very good tool for obtaining seriations of material culture. This index is statistically based on the Hamming distance (simple matching coefficient), which is linear to a Euclidean distance (Sibson et al. 1981). It differs from the Hamming distance in an adjustment for archaeological data: the shared negative features of two sites do not have the same amount of information as the shared positive features. ${ }^{1}$ There are also other good indices for similarity (or distance) of sites; for instance, the Bray-Curtis index, which also gave good results in an empirical investigation but behaves in only a semi-metric fashion (Legendre and Anderson 1999).

\section{The non-linear model/estimation}

Having a model of cultural development versus time at hand, a third step would be to implement this model to estimate dates for sites that are not absolutely dated. This can be done using non-linear estimators such as LOESS (locally weighted scatter plot smoothing).

The LOESS method, originally proposed by William Cleveland (1979), is basically a locally optimized polynomial regression for a given window of the data (specified by the span; i.e., the percentage of data used as the window size). In our case, we used a second-degree polynomial. The data for the LOESS model consists of the absolute dates $(x)$ and the quasi-linear mappings of stylistic dissimilarities from the chronologically most relevant rotated dimension of the NMDS (y). In order to improve the generality of the calculated trends, considering the relatively low number of data points, and to reduce the influence of outliers, we used a rather conservative span for the smoothing window. The fitting itself is done by least squares. The resulting model is a smooth description of the data rather than an analytical model, but it can be used to impute the values of missing data, given that the initial data for the model describes the trend sufficiently. We used the 'loess' method from the 'stats' package in the R statistical environment.

In addition, other methods related to Bayesian statistics are available to link the occurrence of different artefact types in dated sites to their presence in undated situations. One possibility would be to use the results from an ordination (CA, NMDS) as prior for a Bayesian model (e.g., Bayliss et al. 2013). In the case of a CA, only the order of sites in the ordination as prior is usable. With the quasi-metric of an NMDS, the actual position can also be utilized for constraining the Bayesian model. For this, we used the ability of Oxcal to build time-depth models and used the cultural progress as a depth variable. Due to the Oxcal algorithm, the result is in general non-linear, but locally linear. This could be overcome by a transformation before the analysis with Oxcal and a re-transformation of the results, but we left this approach aside for a future study.

\section{THE TEST}

The method was tested on two data sets (Fig. 2). The first consists of the different ceramic rim types in the stratigraphically related horizons of the Bronze Age settlement of Bruszczewo (Poland); the other is based on the closed grave finds and domestic features from the Salzmünde burials of the Middle Elbe-Saale region. In the first instance, we test our method on a single site, where both a vertical stratigraphy and ${ }^{14} \mathrm{C}$ dates are available to assess the chronological relevance

${ }^{1}$ Most of the sites will have shared negative features; that is, not the same types of artefacts in the assemblages. Not having the same type of artefact does not provide the same amount of information like sharing an artefact. 


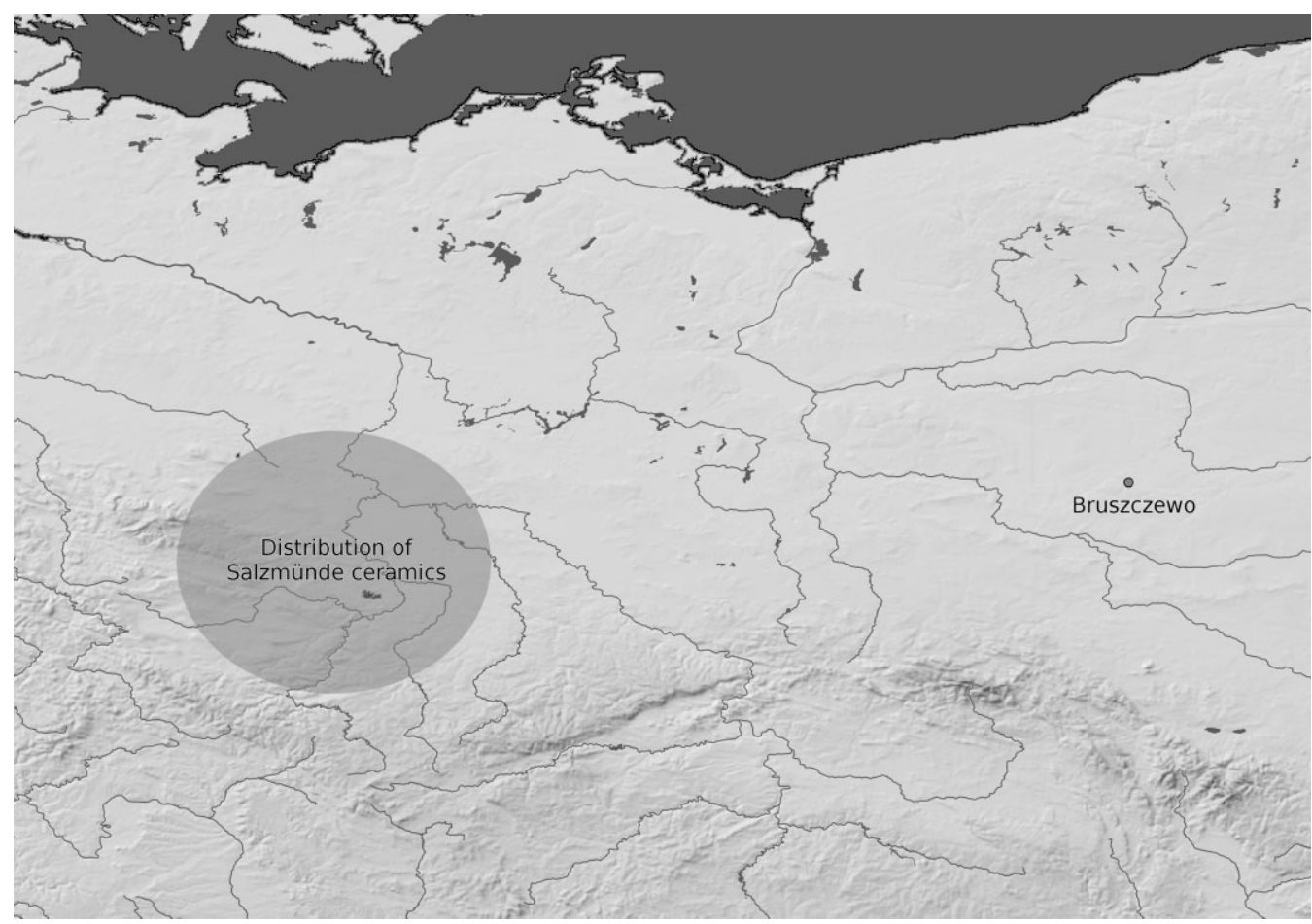

Figure 2 The location of the Bruszczewo EBA site and the distribution of the Salzmünde ceramics.

of differences in material culture. In the second instance, a regional grouping, which was reached by regular similarities in material culture of different sites, will be evaluated. Again, ${ }^{14} \mathrm{C}$ dates are a main source to rate the chronological relevance of differences in material culture. In spite of dealing with two different spatial scales (local and regional), the changing speed of the investigated typological changes could be used as a proxy in both cases for the innovation rate of a local (Bruszczewo) community and a regional network (Salzmünde).

\section{Example 1: early Bronze Age development in Bruszczewo}

The site Bruszczewo is a fortified Early Bronze Age (EBA) settlement in the so-called NorthEast Unetice area (2100-1600 BC). A further occupation of the site is - as a result of the Late Bronze Age - of Lusatian character (1300-550 BC). The material culture and spatial organization allow for a reconstruction of environmental change, the economy, social development and the political institutions of the EBA society (Czebreszuk and Müller 2004; Müller 2010). The consumptive representation of wealth in nearby individual burials indicates a kind of social power that rests on the control of international networks. Access to such networks, which regulate the flow of knowledge and commodities, is governed by social differences. Within the settlement, a constant spatial divergence of production and consumption areas and indications of private ownership suggest stable political institutions that guarantee social stratification.

At the end of the EBA in Bruszczewo, the technological knowledge associated with the metallurgical circle was no longer restricted to a few central sites. Furthermore, the 
dendrological, pollen analytical, archaeobotanical and pedological dates suggest an uncontrolled over-exploitation of the local environs (Bork 2010; Diers 2010; Kroll 2010; Wazny 2010). Obviously, at least a local 'crisis' terminated in a collapse of the social system and the abandonment of the locality. To prove such a model of change, not only a quantification of environmental and economic aspects is necessary, but also one of the cultural constitution of the society. While different economic and ecological proxies indicate changes in time on a quantified scale, this was nevertheless very difficult for the remains of the cultural development. One possibility for 'measuring' changes in cultural productivity or the variability of designs in material culture is the exploration of changes in ceramics, including both decoration and shape. Therefore, quantitative differences in ceramic shapes were used as an indicator of quantitative ratios by using NMDS.

Ceramics Ceramics are among the most frequent artefacts in Bruszczewo (Fig. 3). A comparison of vessel shapes as well as comparisons of the decoration patterns can lead to statements about common characteristics and differences between settlement areas. In order to prevent the functional differences of different areas of the site from influencing the composition of the material culture, the ceramic assemblages for this analysis originate from the waterlogged part of the site. Here, a clear vertical stratigraphy and different dendrological and ${ }^{14} \mathrm{C}$ dates allowed a clear chronological differentiation of the assemblages, independent of any typological considerations. Thus, to obtain the temporal vector as a primary ordination criterion, only the 1856 ceramic units of the waterlogged area were used for a NMDS.

Absolute dates As a value for the estimation of the speed of cultural development, we used the overall results of scientific dates for the absolute chronology. The vertical stratigraphy enabled us to separate eight successive settlement horizons. While samples for dendrological and AMS dates were available from archaeological features for horizons 2 and 3, AMS dates could be obtained for horizons 4, 6 and 8, and for the earliest indications of anthropogenic presence before settlement activities (horizon 0). Furthermore, AMS dates of intra-site pollen analysis were available for horizons $1-5$ and 7 . Both the $1 \sigma$ sum calibration of each horizon and a sequential calibration were used to produce a chronological model, which was counterchecked by the ${ }^{14} \mathrm{C}$ dates from the intra-site pollen analyses (Müller 2010). As a result, the absolute age spans of horizons 1-5 were obtained as well as their mean ages (Table 1). For analytical reasons, the mean ages are also used in the following analysis for younger horizons for which the absolute dates are not as secure.

Results We used the assemblages from the waterlogged area and computed a two-dimensional NMDS solution. The resulting configuration differed significantly from those that were the outcome of a CA (for comparison, see Müller 2010, 775). Two dimensions were chosen because this seems to be the best compromise between a display of the variety and the complexity of the result, as proposed by Drennan (1976). Moreover, the plot of the second versus the third dimension showed that they do not display temporality like that of the first dimension. The stress value of the solution was $6.48 \%$, and thus very low. The plot of the scores of the first principal axes against the ${ }^{14} \mathrm{C}$ data show the different speeds of innovation through time.

The first dimension of the NMDS, which represents chronological development, offers the opportunity to quantitatively show the speed of change. The differences between the coordinates of two phases on that dimension quantify the qualitative similarity or dissimilarity of the 


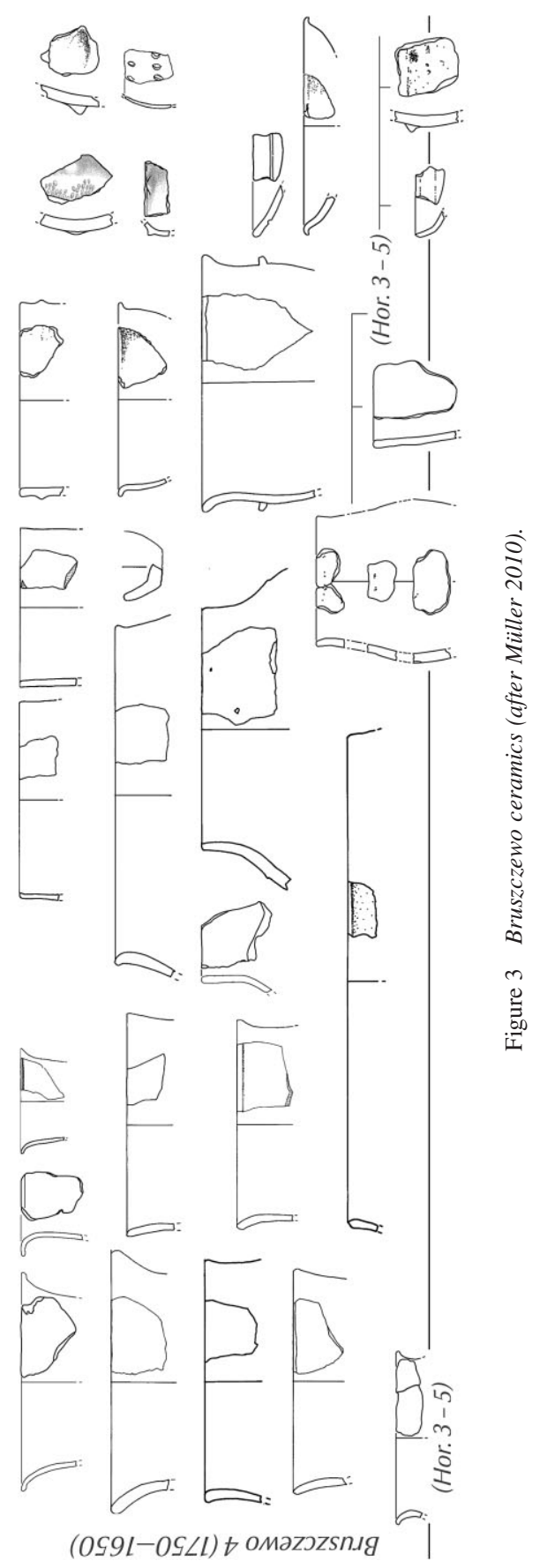



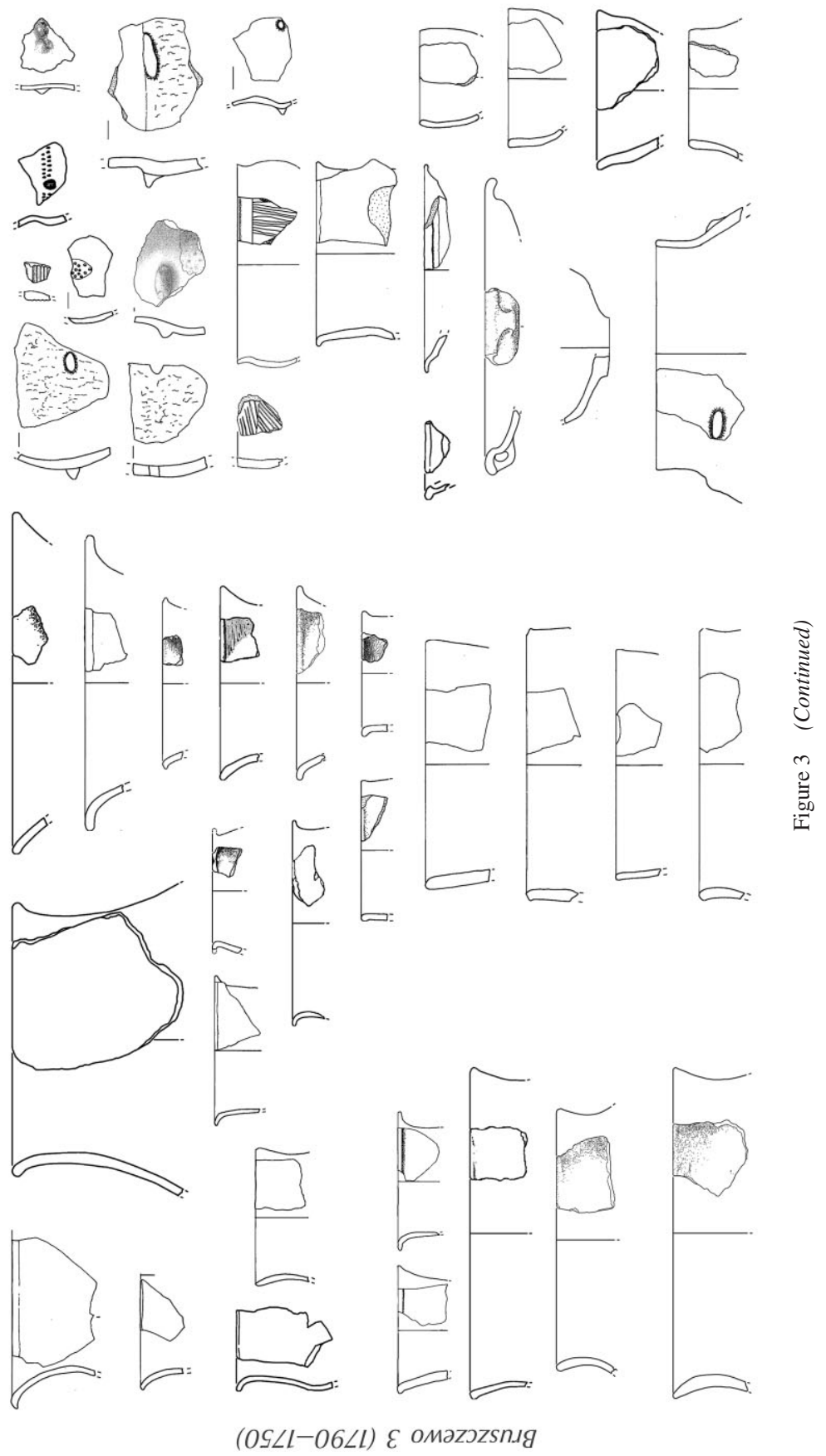


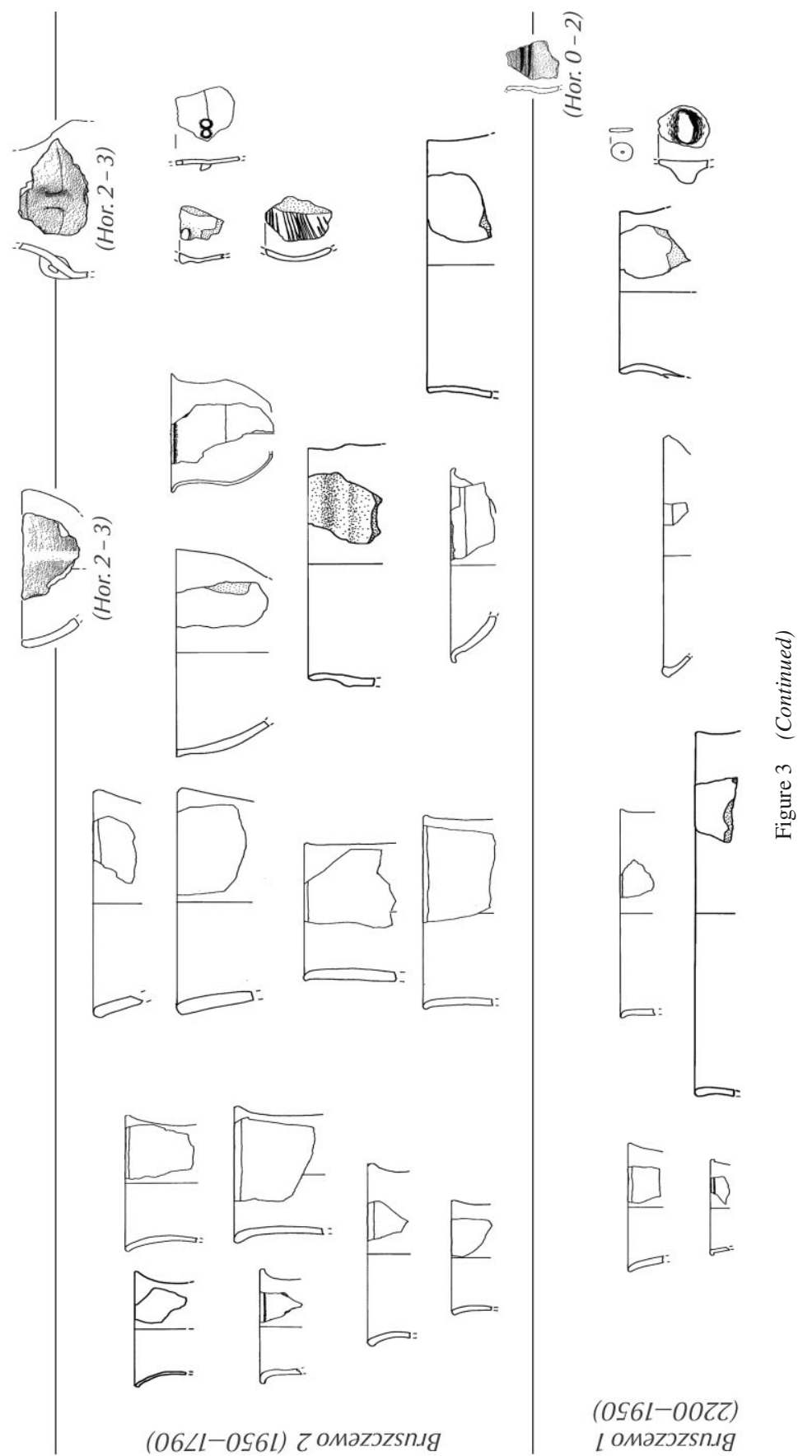


Table 1 Bruszczewo: the absolute timescale (after Müller 2010)

\begin{tabular}{|c|c|c|c|c|c|c|c|}
\hline Horizon & Dendrochronology & ${ }^{14} \mathrm{C}$ SumCal & ${ }^{14} \mathrm{C}$ sequCal & $\begin{array}{c}{ }^{14} \mathrm{C} \text { from } \\
\text { pollen analysis }\end{array}$ & Age & $\begin{array}{l}\text { Mean } \\
\text { age }\end{array}$ & $\begin{array}{l}\text { Used } \\
\text { age }\end{array}$ \\
\hline 8 & & $760-410$ & $825-470$ & & & & 616 \\
\hline 7 & & $760-410$ & & $850-$ & & & 585 \\
\hline 6 & & $970-840$ & $975-850$ & & & & 909 \\
\hline 5 & & & & $1600-$ & $1650-1600$ & 1625 & 1625 \\
\hline 4 & & $1880-1680$ & $1740-1690$ & $1850-1600$ & $1750-1650$ & 1700 & 1700 \\
\hline 3 & $1773 ?$ & $1880-1740$ & $1800-1775$ & $1950-1850$ & $1790-1750$ & 1770 & 1770 \\
\hline 2 & $1797-1792$ & $1860-1740$ & & $2000-1950$ & $1950-1790$ & 1860 & 1860 \\
\hline 1 & & & & $2200-2000$ & $2200-1950$ & 2075 & 2075 \\
\hline
\end{tabular}

inventories (which does not mean quantitative differences, for example, in the number of respective types that were discussed above). Thus, the curves of Figure 4 reflect the speed of typological developments in their degree of inclination.

We observe a high speed of change in vessel shapes and decorative patterns between 2100 and $1850 \mathrm{BC}$. This high innovation rate contrasts with the development between 1850 and $1700 \mathrm{BC}$, where the rate of change slows down to zero, and in about five generations no significant changes in material culture are observable. Between 1700 and 1650 BC, typological differences increase again, which might be due to severe problems in the community (see below). Further indications in Figure 4 should not be overestimated, as a gap in domestic activities is followed by smooth changes in ceramic typology during the Lusatian period. We included the culturally very different Lusiatian period in our analyses in spite of the fact that a clear break is expected by most archaeologists. Unfortunately, in Bruszczewo, as at every other known site, the mentioned gap hinders us in verifying the idea of the cultural break.

To summarize, the results for Bruszczewo indicate an initial phase with a fast development of material culture, followed by a stabilization phase during the stable phase of the settlement. Together with the botanical and ecological data, this sequence can be interpreted. Simultaneous with the onset of the ecological problems of the site, the material culture also underwent increasing change. The colluvial sediments of the main ditch, which most probably date to the 17th century BC (Hildebrandt-Radke 2010, 35), indicate the end of the settlement activities. Also, the palynologically detected decline of the human impact falls within the same timescale and confirms the cessation of domestic activities (Diers 2010; Haas and Wahlmüller 2010). Moreover, soil scientists have reconstructed reforestation on site (Bork 2010). Contemporaneous with these shifts, the production rate, the variability of the decoration and the extent of storage facilities also decreased (Müller 2010).

Interpretation Taking architecture into consideration-in particular, the fortifications-the time frame for the settlement is revealed. In the western area of the settlement, the multiple renewal of a palisade, which covers the period between 2050 and 1650 BC (Czebreszuk and Müller 2004, 297), has been verified. In the north, a segmented ditch was also established in the 21st century BC and colluvial sedimentation within the ditch began in the 17th preChristian century. The principal settlement activities might have taken place between 2050 and 1650 BC. 


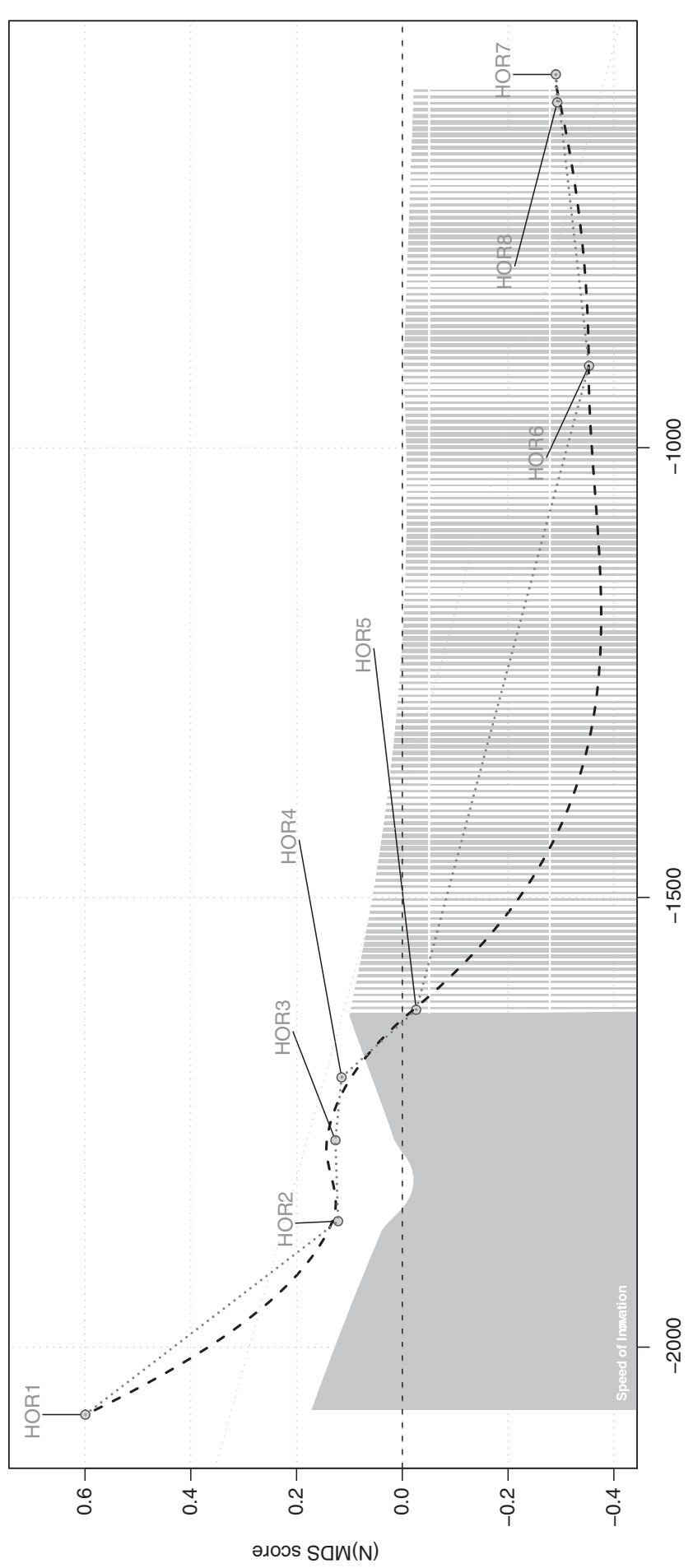

$\stackrel{3}{3}$

के 
The main residential activities in the eastern wet area possibly began in about 1790 BC. An enlargement is marked by an additional fortification. The newly enclosed area was used for work activities as well as for new house structures. The settlement activities in this area end here, as indicated by a lake transgression with sudden flood events, possibly in about $1650 \mathrm{BC}$.

As indicated by the ecological data, the climax of general settlement development was reached at approximately $1800 \mathrm{BC}$. On-site pollen analyses prove cereal production, pasture, forest use and clearances beginning at the latest in the 21st pre-Christian century (Diers 2010, 353ff.). At approximately 1800 BC, an extensively used environment was evident, with only a few remaining forest areas, which resemble park-like landscapes. These were pressurized in turn by agriculture and extensive cattle herding. In particular, Lake Samica exhibited a high level of pollution. The dendrochronological results refer to difficulties in the provision of timber (Wazny 2010, 237): wood was chopped unsystematically from the few locations still available and no cultivated timber was at hand. Beginning at c.1750 $\mathrm{BC}$, forest regeneration was already noticeable with remaining open spots, pointing to the reduction of economic activities on the site.

In consequence, the rate of cultural change can clearly be linked to economic activities and ecological problems. During a phase of settlement expansion, the rate of innovation (either as autonomous innovation or as the disposition to be affected by external influences) was also very high in material culture. During a phase of stability, no further innovations were reflected in material culture, while during a time of economic and ecological crisis, a newly increasing innovation rate possibly reflected an unsuccessful will to collectively tackle problems with new ideas. Nevertheless, the site was first abandoned after 1650 BC.

\section{Example 2: middle Neolithic Salzmünde}

The sites In contrast to the EBA case study, example 2 deals with the temporal development of a style group within a certain region. From 90 sites in the Middle Elbe-Saale region of Central Europe, pottery is known that has been labelled after the eponymous site of 'Salzmünde', near Halle (Beran 1993; Müller 2001). In addition to the different shapes and decoration patterns, which are also known from other ceramic styles in the region between c.3800 and $2800 \mathrm{cal}$ BC, the 'Opperschöner Kanne' represents a kind of index find-in many cases, a vessel with a ladder motif on its shoulders. This kind of pottery is known from single and collective burials, domestic structures and causewayed enclosures. As 'Salzmünde' ceramics are associated with many economic and political changes that took place in the Middle Neolithic of densely populated central Germany (also visible in other remains of archaeological features and material culture), the chronology of the ceramic style has been discussed controversially over recent decades (Müller 2009). As changes in ceramic design (both shape and decoration patterns, see below) might be useful as a proxy for the speed and direction of cultural changes, we used 85 closed finds from settlements, burials and enclosures for similarity analyses; that is, CA and NMDS. In both analyses, clear gradients could identify typological differences.

Ceramics Figure 5 shows the ceramic types and decorations of the data set placed according to their position in the NMDS, first and second dimension. In general, the analyses differentiate a sequence of assemblages with: (1) four-lugged amphorae, funnel beakers and Arcadic rims; (2) steep-walled, handled vessels and bowls with cylindrical upper parts and decorated with ladder motifs; (3) 'Opperschöner Kannen' carinated cups and decorations with zigzags and triangles; and (4) profiled cups and jugs, as well as biconical drums, decorated with a variety of geometric 


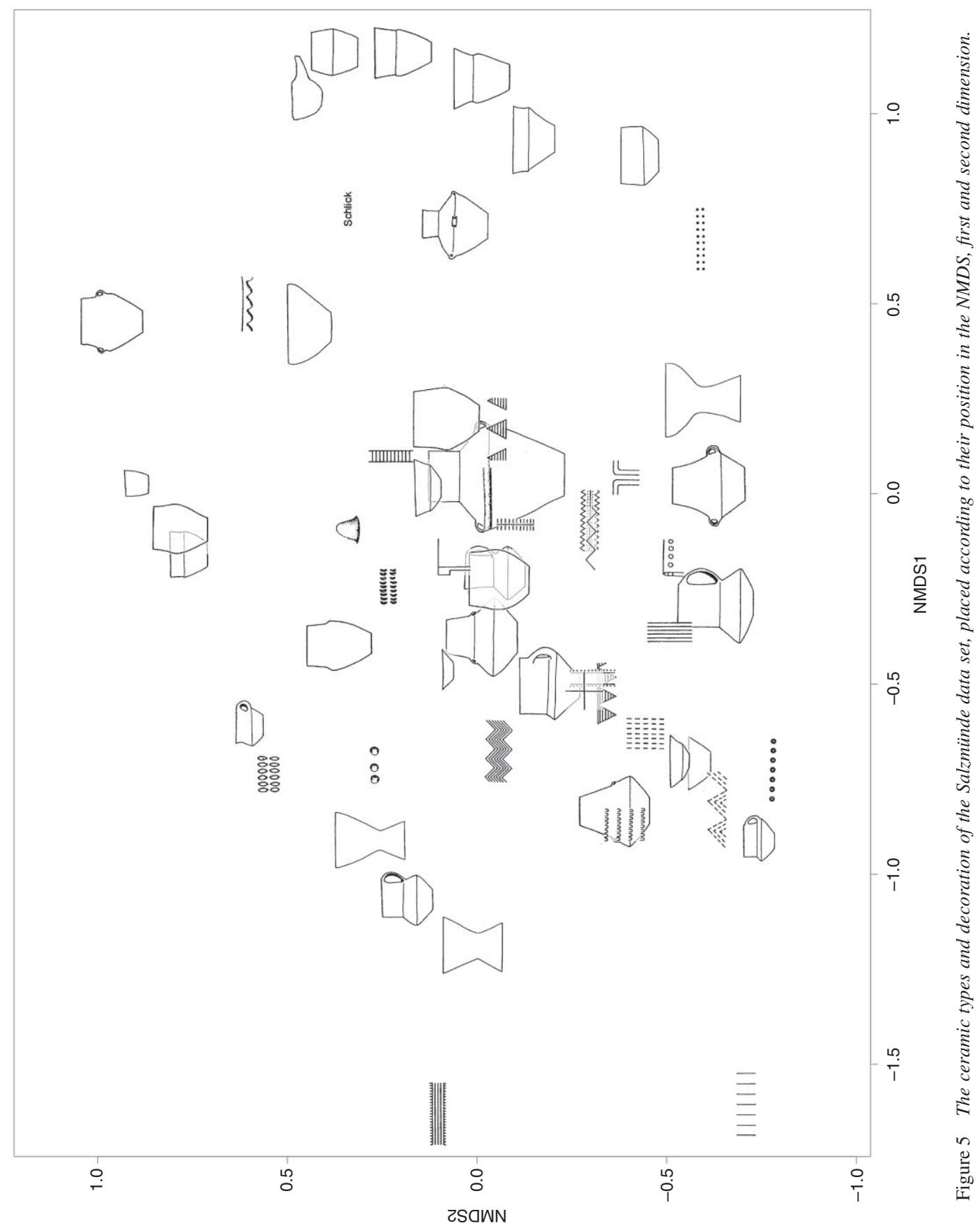


decorations. The lack of spatial differences in the distribution of these typological groups of assemblages supports the opinion that we are dealing with chronologically relevant groups. Indeed, the available ${ }^{14} \mathrm{C}$ data prove, in principle, the chronological relevance of these typological ceramic differences. Furthermore, associations with other pottery styles in closed assemblages are in line with the gained chronological model.

Absolute dates There are $25{ }^{14} \mathrm{C}$ dates or combined calibrations available for the data set. Table 2 shows the dates for the different sites. Several dates were excluded from the modelling procedure for different reasons. The dates for Köthen-Junkers Motorenfabrik (KOEJU3) were excluded because the combined ${ }^{14} \mathrm{C}$ calibration showed a bad combination of dates at a $5 \%$ level. The date for Wallendorf-Hutberg feature 138 was taken from animal bones, which probably belong to the floor of an overlying house structure (Benesch 1941, plate 4, figs 5 and 6). The chamber graves of Nordhausen 2 (NordhauA), Niederbösa (NiederB) and Schönstedt (Schoenst) are dominated by non-Salzmünde ceramics, so that the absolute dates are probably associated with those ceramics. This is probably due to a longer use of the graves than is indicated by the single-event ${ }^{14} \mathrm{C}$ dates (Müller 2001, 122). The dates for the Erfurt-Gispersleben Pit 37 site were ignored because it was obvious that this pit contained very inhomogeneous material (Müller 2001, 119).

Twelve dates, or combinations of dates, remained to build a model of the temporal versus cultural development of the Salzmünde ceramics.

Results For the values of the absolute dates, we used the mode of probability for the calibrated date from the raw output of Oxcal. If there were two modes, we used their mean. We used an iterative approach to identify the solution and dimension that fitted the ${ }^{14} \mathrm{C}$ data best by computing all solutions between 1 and 20 dimensions and testing which one had the highest correlation of the NMDS scores of the dated assemblages with the absolute dates. This was the first dimension of a four-dimensional solution. The stress value of this solution was $14.5 \%$, and thus also very low. The ${ }^{14} \mathrm{C}$ data correlated with the NMDS scores is highly significant $(p<0.001$, Kendall) with a correlation of $0.91(\tau)$. We used Kendall's $\tau$ rank correlation coefficient because we did not want to superimpose linearity on the model.

Having that model at hand, we estimated the absolute dates for the whole sample of ceramic assemblages. For this, we used the LOESS method to calculate a smooth trend in the development. The smoothing parameter was optimized to fulfil the Akaike information criterion (AICc for small samples) as a measurement of goodness of fit of the model. The resulting span was 0.783 .

The diagram (Fig. 6) shows the result. The error ranges are one with respect to two standard errors for the estimated absolute date, calculated from the LOESS model.

Interpretation In the Salzmünde case, we do not see a steep development of the ceramic forms at the beginning. Once the cultural form has been found, there is a stable phase, with many sites following the generally established cultural scheme. Around $3200 \mathrm{cal} \mathrm{BC}$, the model predicts a change in the cultural pattern, leading to an increased development of the material cultureperhaps a dynamic announcing a major change in the cultural system. This correlates quite well with the steep rise in the relative quantity of axes in the graves (Müller 2001, 402, fig. 248), as well as with the extent of the copper artefacts in the area (Müller 2001, 414, fig. 254). This indicates that the major shift towards the complex society of the final Late Neolithic is prefigured in the increased introduction of new stylistic elements. 


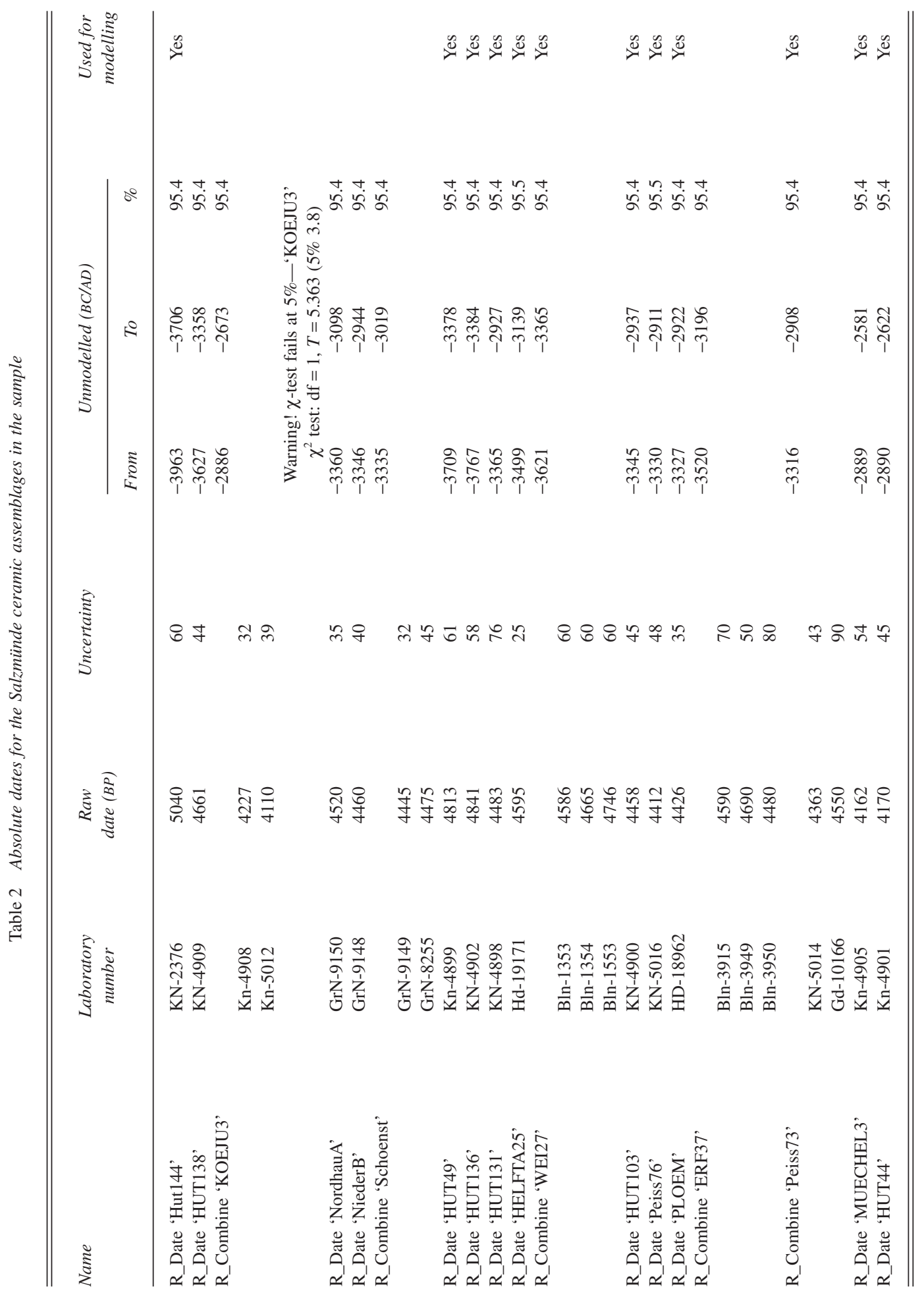




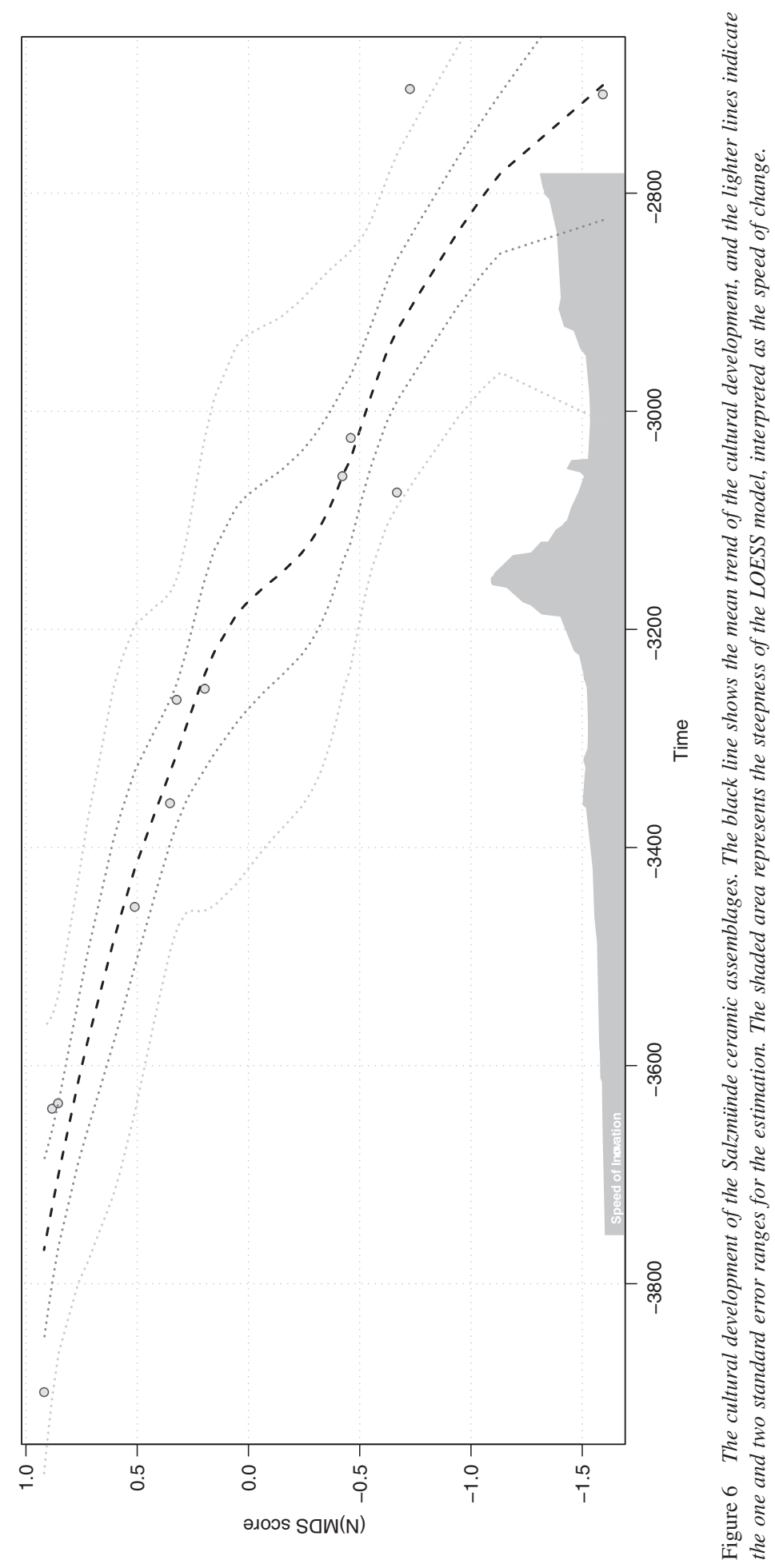

(C) 2014 University of Oxford, Archaeometry 57, 3 (2015) 560-581 


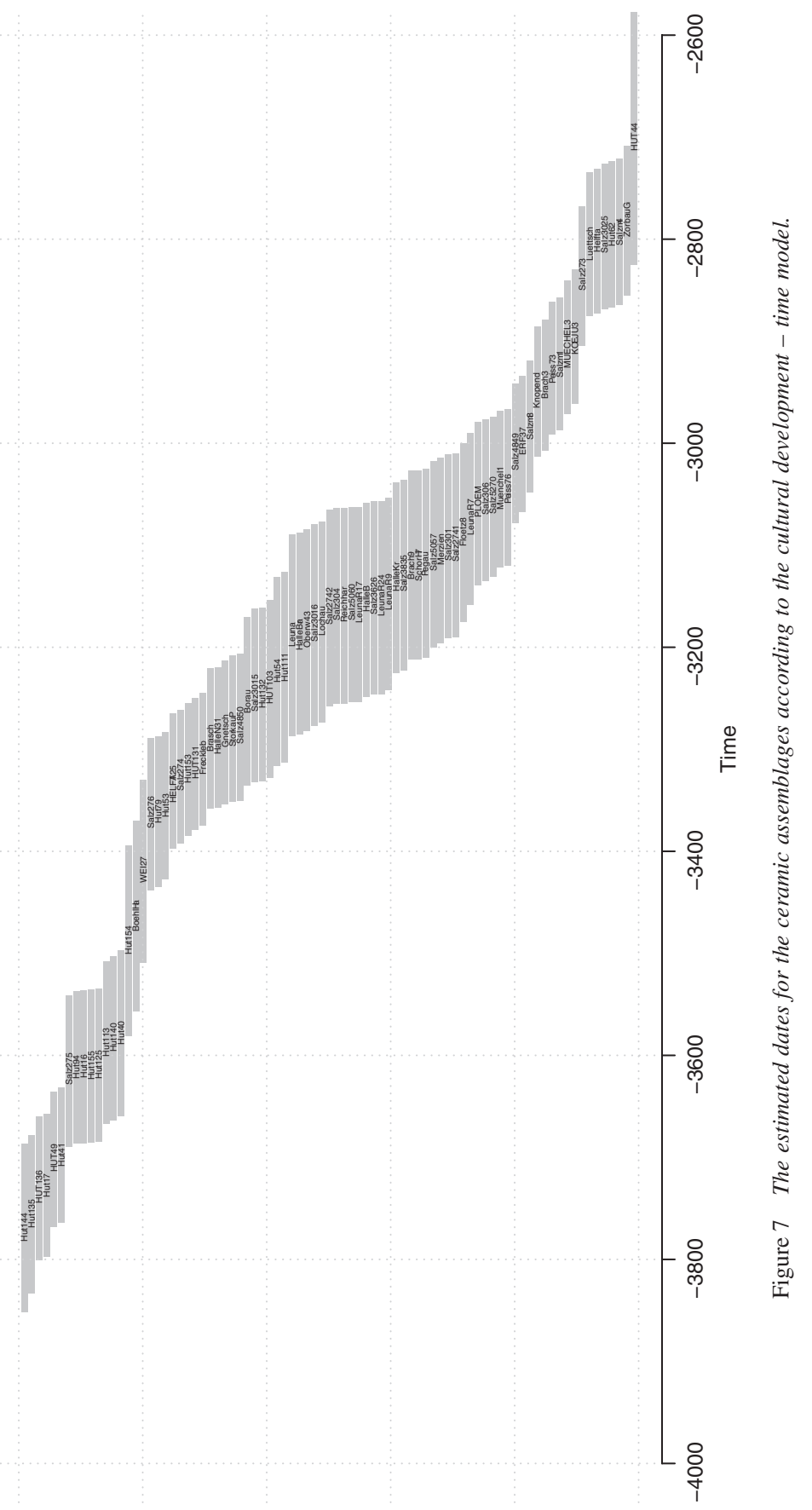


Overall, a changing rate in the innovation of new ceramic shapes and decoration patterns is quantified and this quantification mirrors the changes in material cultures shortly after 3200 cal BC.

\section{RESULTS AND EVALUATION}

In our opinion, the use of NMDS to mirror the speed of change in ceramic developments of one site with stratified phases (example 1) and of a region with different sites (example 2) is very promising. The changing rate of the speed of cultural development - at least, of ceramic shapeswas quantified. In addition to this methodological success, the curve (the 'innovation rate') was useful in combination with other information: changes within the society are thus visible at various distinct points of detection.

From a methodological point of view, both the quantification of cultural processes as well as the quantitative description of change enable us to compare, for example, ecological proxies with cultural proxies.

A further side effect might also be important. While the stratigraphical calibration of ${ }^{14} \mathrm{C}$ dates on a Bayesian basis allows one to use semi-linear models for the estimation of the dating of non-dated events (e.g., Bayliss et al. 1997, 2007), with the non-linear estimator (here, LOESS), it is possible to use a non-linear model for estimating the absolute timescale of sites dated with relative dating (Fig. 7). This estimation depends on the accuracy and validity of the model in the first place and it improves with every additional ${ }^{14} \mathrm{C}$ date available, but it can also be a valuable tool for situations in which sites are not scientifically datable but are likely to fit well into the general scheme of development of a cultural sequence. Figure 6 shows that most of the dated sites lie within the $1 \sigma$ range of the estimation. A 'leave one out' test, where, one by one, sites were omitted during the model building, proved this result.

\section{CONCLUSION}

With the help of multidimensional scaling, it is possible to link a linear process, such as time, with a non-linear process, in this case cultural development. The investigated cultural changes were plotted on a linear scale. The advantage of the method (in contrast, for example, to CA) is that the factor values of different assemblages are also quantified on a comparable basis, and thus the cultural information is useful for the following aspects:

(1) to calculate the speed of changes in material culture; and

(2) to estimate the absolute date for sites dated with relative dating.

\section{ACKNOWLEDGEMENTS}

We benefited from very interesting comments by Marie-Josée Nadeau, Eileen Kücükkaraca, Stephen Shennan, the reviewers and many others to whom we are grateful. This research was supported by the 'Human Development in Landscapes' Graduate School at the CAU Kiel.

\section{REFERENCES}

Bayliss, A. B., Bronk Ramsey, C., and McCormac, F. G., 1997, Dating Stonehenge, in Science and Stonehenge: proceedings of the British Academy 92 (eds. B. Cunliffe and C. Renfrew), 39-60, Oxford University Press, Oxford.

Bayliss, A. B., Galer, D., Humphrey, L., McFayen, L, and Whittle, A., 2007, One thing after another: the date of the Ascott-under-Wychwood Long Barrow, Cambridge Archaeological Journal, 17(1), 29-44. 
Bayliss, A., Hines, J., Nielsen, K. H., McCormac, G., and Scull, C., 2013, Anglo-Saxon graves and grave goods of the 6th and 7th centuries AD: a chronological framework, SMA Monograph 33, Society for Medieval Archaeology, Leeds.

Bellanger, L., Husi, Ph., and Tomassone, R., 2006, Statistical aspects of pottery quantification for the dating of some archaeological contexts, Archaeometry, 48, 169-83.

Bellanger, L., Husi, Ph., and Tomassone, R., 2008, A statistical approach for dating archaeological contexts, Journal of Data Science, 6, 135-54.

Benesch, F., 1941, Die Festung Hutberg. Eine jungnordische Mischsiedlung bei Wallendorf, Kr. Merseburg, GebauerSchwetschke Verlag, Halle.

Beran, J., 1993, Untersuchungen zur Stellung der Salzmünder Kultur im Jungneolithikum des Saalegebietes, Beier \& Beran, Wilkau-Hasslau.

Bork, H.-R., 2010, Archäologische und umweltgeschichtliche Untersuchung eines markanten Sporns am westlichen Talrand der Samica, in Bruszczewo II. Ausgrabungen und Forschungen in einer prähistorischen Siedlungskammer Großpolens (eds. J. Müller, J. Czebreszuk and J. Kneisel), 38-49, Studien zur Archäologie in Ostmitteleuropa 6, Verlag Dr Rudolf Habelt, Bonn.

Cleveland, W. S., 1979, Robust locally weighted regression and smoothing scatterplots, Journal of the American Statistical Association, 74(368), 829-36.

Czebreszuk, J., and Müller, J., 2004, Zur absolutchronologischen Datierung des Siedlungsgeschehens, in Bruszczewo I. Ausgrabungen und Forschungen in einer prähistorischen Siedlungskammer Großpolens (eds. J. Czebreszuk and J. Müller), 293-310, Studien zur Archäologie in Ostmitteleuropa 2, VML, Rahden/Westf.

Diers, S., 2010, Feinstratigrafie und Chronologie: Archäologische und palynologische Analysen. Eine Fallstudie zum Fundplatz Bruszczewo 5 in Großpolen, in Bruszczewo II. Ausgrabungen und Forschungen in einer prähistorischen Siedlungskammer Großpolens (eds. J. Müller, J. Czebreszuk and J. Kneisel), 335-460, Studien zur Archäologie in Ostmitteleuropa 6, Verlag Dr Rudolf Habelt, Bonn.

Drennan, R. D., 1976, A refinement of chronological seriation using nonmetric multidimensional scaling, American Antiquity, 41(3), 290-302.

Graham, I., Galloway, P., and Scollar, I., 1976, Model studies in computer seriation, Journal of Archaeological Science, 3, 1-30.

Groenen, P. J. F., and Poblome, J., 2003, Constrained correspondence analysis for seriation in archaeology applied to Sagalassos ceramic tablewares, in Exploratory data analysis in empirical research (eds. M. Schwaiger and O. Opitz), 90-7, Springer-Verlag, Berlin.

Haas, J. N., and Wahlmüller, N., 2010, Floren-, Vegetations- und Milieuveränderungen im Zuge der bronzezeitlichen Besiedlung von Bruszczewo (Polen) und der landwirtschaftlichen Nutzung der umliegenden Gebiete, in Bruszczewo II. Ausgrabungen und Forschungen in einer prähistorischen Siedlungskammer Großpolens (eds. J. Müller, J. Czebreszuk and J. Kneisel), 50-81, Studien zur Archäologie in Ostmitteleuropa 6, Verlag Dr Rudolf Habelt, Bonn.

Hildebrandt-Radke, I., 2010, Das geologische Alter und die Hauptphasen der Denudations- und Akkumulationsprozesse vor dem Hintergrund topografischer Verhältnisse des archäologischen Fundplatzes Bruszczewo, in Bruszczewo II. Ausgrabungen und Forschungen in einer prähistorischen Siedlungskammer Großpolens (eds. J. Müller, J. Czebreszuk and J. Kneisel), 16-37, Studien zur Archäologie in Ostmitteleuropa 6, Verlag Dr Rudolf Habelt, Bonn.

Jørgensen, L., 1992, Chronological studies of Anglo-Saxon England, Lombard Italy and Vendel Period Sweden, Institute of Prehistoric and Classical Archaeology, Copenhagen.

Kendall, D. G., 1969, Some problems and methods in statistical archaeology, World Archaeology, 1(1), Recent work and new approaches, 68-76.

Kroll, H., 2010, Die Archäobotanik von Bruszczewo-Darstellung und Interpretation der Ergebnisse, in Bruszczewo II. Ausgrabungen und Forschungen in einer prähistorischen Siedlungskammer Großpolens (eds. J. Müller, J. Czebreszuk and J. Kneisel), 250-89, Studien zur Archäologie in Ostmitteleuropa 6, Verlag Dr Rudolf Habelt, Bonn.

Kruskal, J. B., 1964, Nonmetric multidimensional scaling: a numerical method, Psychometrika, 29, 115-29.

Legendre, P., and Anderson, M. J., 1999, Distance-based redundancy analysis: testing multispecies responses in multifactorial ecological experiments, Ecological Monographs, 69(1), 1-24.

Madsen, T., 1988, Multivariate statistics and archaeology, in Multivariate archaeology: numerical approaches in Scandinavian archaeology (ed. T. Madsen), 7-28, University Press, Århus.

Montelius, O., 1903, Die älteren Kulturperioden im Orient und in Europa, 1: Die Methode, Selbstverlag des Verfassers, Stockholm.

Müller, J., 2001, Soziochronologische Studien zum Jung- und Spätneolithikum im Mittelelbe-Saale-Gebiet (4100-2700 v. Chr.). Eine sozialhistorische Interpretation prähistorischer Quellen, Leidorf, Rahden/Westf.

Müller, J., 2009, Dating the Neolithic: methodological premises and absolute chronology, Radiocarbon, 51, 721-36. 
Müller, J., 2010, Bruszczewo 5: production, distribution, consumption, and the formation of social differences, in Bruszczewo II. Ausgrabungen und Forschungen in einer prähistorischen Siedlungskammer Großpolens (eds. J. Czebreszuk and J. Kneisel), 756-82, Studien zur Archäologie in Ostmitteleuropa 6, Verlag Dr Rudolf Habelt, Bonn.

Müller, J., and Zimmermann, A. (eds.), 1997, Archäologie und Korrespondenzanalyse. Beispiele, Fragen, Perspektiven. Internationale Archäologie, Leidorf, Espelkamp.

Petrie, F. W. M., 1899, Sequences in prehistoric remains, The Journal of the Anthropological Institute of Great Britain and Ireland, 29(9/4), 295-301.

Renfrew, C., and Bahn, P., 2000, Archaeology: theories, methods, practice, 3rd edn, Thames \& Hudson, London.

Shennan, S., 1988, Quantifying archaeology, Edinburgh University Press, Edinburgh.

Sibson, R., Bowyer, A., and Osmond, C., 1981, Studies in the robustness of multidimensional scaling: Euclidean models and simulation studies, Journal of Statistical Computation and Simulation, 13(3), 273-96.

van de Velden, M., Groenen, P. J. F., and Poblome, J., 2009, Seriation by constrained correspondence analysis: a simulation study, Computational Statistics and Data Analysis, 53(8), 3129-38.

Wazny, T., 2010, Bericht zur dendrochronologischen Datierung von Bruszczewo, Grabungen 2004-2005, in Bruszczewo II. Ausgrabungen und Forschungen in einer prähistorischen Siedlungskammer Großpolens (eds. J. Müller, J. Czebreszuk and J. Kneisel), 233-7, Studien zur Archäologie in Ostmitteleuropa 6, Verlag Dr Rudolf Habelt, Bonn. 